\title{
Measurement of gross alpha activity and statistical analysis of beach sediments along southern coastal region of TamilNadu
}

\author{
A.Priya Latha, G.Shanthi \\ Department of Physics \& Research Centre, Women's Christian College, Nagercoil, India, 629001
}

\begin{abstract}
Radioactivity is a part of our environment. Natural radionuclides in soil generate a significant component of the background radiation exposure to the population. Radiation becomes a concern when these particles and energy come in contact with molecules inside the human body. This paper evaluates the radioactivity concentration of beach sand samples collected from the south east region of Tamilnadu. 20 beach sand samples are collected from the different locations of Tamilnadu. A survey of the gross alpha activity has been done using alpha scintillation counter. The gross alpha activity in the sand samples near the sea are found to be maximum (3679.6 Bq/kg) in Kol of sieve size $0.250 \mathrm{~mm}$ and minimum $(162.3 \mathrm{~Bq} / \mathrm{kg})$ in Aal and Mal of sieve size $0.025 \mathrm{~mm}$ respectively. Also, the results showed the gross alpha activity in the beach sand samples 150 $m$ away from the sea is maximum $(1774.1 \mathrm{~Bq} / \mathrm{kg})$ in Pml5 and minimum $(107.5 \mathrm{~Bq} / \mathrm{kg})$ in Pe5 respectively. Statistical analysis has also been carried out to find the significant differences in the samples.
\end{abstract}

\section{Introduction}

Human beings are always exposed to ionizing radiation that are present in different types of natural sources all the time. Radioactivity in soil is mainly due to the presence of radioactive elements in the earth's crust and those coming from the outer space to the atmosphere. The radioactivity level from the natural radionuclides is termed as background radiation which will depend on the amount of the radioactive materials in the environment. The background radiation can be high if the environment is polluted either from man-made or natural activities. Naturally occurring radionuclides in earth's crust are strongly influenced by the local geological and geographical conditions[1]. Materials from the deposit of mineral sources may be brought to the surface soil through processes such as weathering of rocks and soil formation[2]. The most commonly encountered radionuclides are ${ }^{238} \mathrm{U},{ }^{232} \mathrm{Th}$ and ${ }^{40} \mathrm{~K}$. The naturally occurring radionuclides in earth's crust are strongly influenced by the local geological and geographical conditions. Cosmic radiation and terrestrial radiation arising out of earth's crust give rise to the external exposure and inhalation of natural/man-made radionuclides that are present in the environment forms due to internal exposure [3]. Artificial radionuclides emitted from nuclear power plants and industrial plants has smaller contribution to the overall radiation. Soil radioactivity concentration is one of the main determinants of the natural background radiation. Terrestrial sources of naturally occurring radionuclides that are present in soil affect environment[4]. Radioactive decay can involve a variety of emissions, including alpha particles, beta particles, and gamma rays. Alpha-emitting materials can be harmful to humans if the materials are inhaled, swallowed, or absorbed through open wounds. Ionizing radiation can disrupt atoms, creating positive ions and negative electrons, and cause biological harm. Ionizing radiation includes x-rays, gamma rays, alpha particles, beta particles, neutrons, and the varieties of cosmic rays. Alpha particles are emitted from the nuclei of many heavy radioactive atomic nuclei during decay. ${ }^{222} \mathrm{Rn}$ is an inert radioactive element occurs in soil gas in varying concentrations. High radiation levels can occur by naturally occurring radioactive materials in the rocks, soils, sediments etc. The exposure to ionizing radiation create health hazard to people. Several studies have been carried out for the measurement of radioactivity concentration in soil[5-10]. In order to assess the exposure of radiation to the general public due to the sources, it is essential to collect the data as possible. The main objective of the present work is to estimate the level of gross alpha activity in the beach sand samples taken from various locations. The results of the present study may be useful as a baseline data for future purpose.

\section{Materials and Methods}

The south east region of TamilNadu is chosen for the present study. All these areas located in the coastal belt of TamilNadu. The sampling locations are located between $8^{\circ} 47^{\prime}$ of north of latitude and $78^{\circ} 8^{\prime}$ of east of longitude. The soil samples are collected from 20 different sites from Ko1 to Mtm1 and Ko5 to Mtm5. To avoid any surface contamination, each sample is taken at a depth of $10 \mathrm{~cm}$. The samples are air-dried, crushed into fine powder, divide and sieved through $0.250 \mathrm{~mm}, 0.063 \mathrm{~mm}$ and $0.025 \mathrm{~mm}$, homogenized and stored in plastic bags. Each sample is stored in a plastic bag and kept for about 30 days to allow radioactive equilibrium among thorium and uranium and their decay products. Determination of the gross alpha radioactivity concentration in the samples are made by using Alpha counter with $\mathrm{ZnS}(\mathrm{Ag})$ scintillator. 


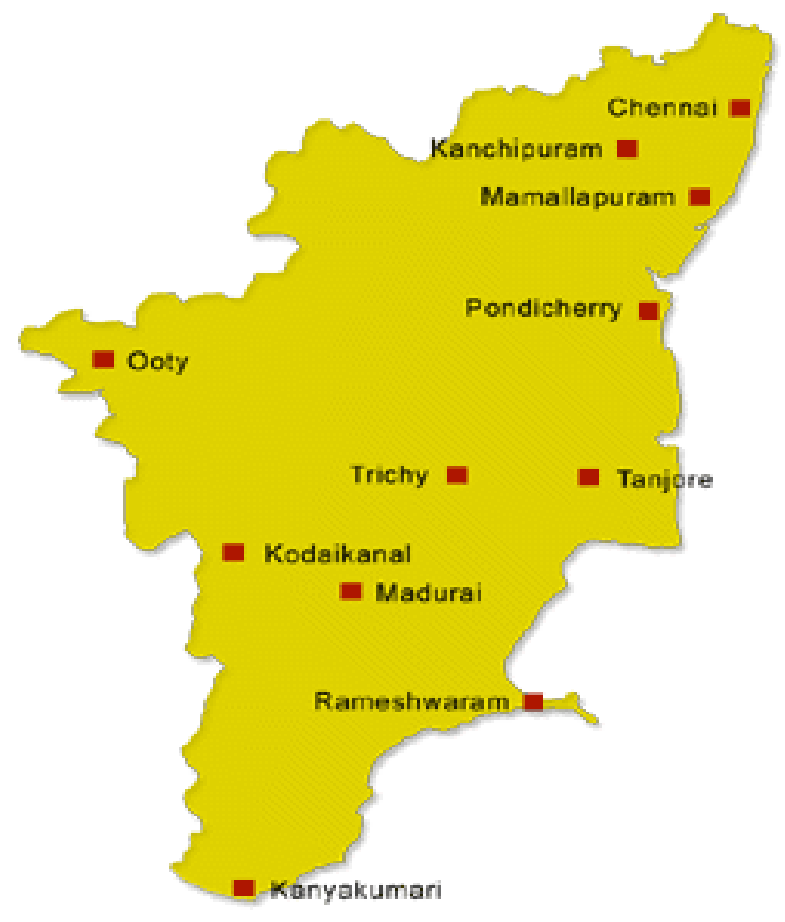

\begin{abstract}
Alpha Counter
Gross alpha counting is performed by $\mathrm{ZnS}(\mathrm{Ag})$ scintillation alpha counter. The Alpha Probe AP185 radiation counting system is used for the detection of alpha particles. About $0.06 \mathrm{gm}$ of powdered sample is taken in an aluminium planchet. The planchet was kept in the alpha counter for a period of 1000 seconds and the counts are noted. The instrument is standardized with the help of standard source and its counts are noted. The background of the alpha counter is determined by counting the empty planchet three times for the same time period and the average is taken as a background of the counter. The gross alpha activity is calculated in Bq/ $\mathrm{kg}$. ${ }^{241} \mathrm{Am}$ source is used for the efficiency calibration of the alpha particle counting system.

The principle of operation of the scintillation counter is outlined as follows. The energy loss suffered by a particle impinging on a scintillation substance triggers the emission of light. This light is delivered by using suitably constructed light guides to a device such as a photomultiplier, which together with suitable electronics, records the light as an electrical signal and hence the particle that caused the emission of light.
\end{abstract}

\title{
III. Results and discussions
}

The gross alpha radioactivity concentrations measured in the beach sand samples obtained from different locations for various sieve size are shown in table 1 . As shown in the table 1, the gross alpha activity varies from $162.3 \mathrm{~Bq} / \mathrm{kg}$ to $3679.6 \mathrm{~Bq} / \mathrm{kg}$ near the sea and ranges from $107.5 \mathrm{~Bq} / \mathrm{kg}$ to $1774.1 \mathrm{~Bq} / \mathrm{kg} 150 \mathrm{~m}$ away from the sea. The sand sample Ko1 has the highest value for the sieve size $0.250 \mathrm{~mm}$ while the alpha activity is lower for the samples Aa1 and Ma1 for the sieve size $0.025 \mathrm{~mm}$ compared with other samples. The maximum alpha activity is observed in Pml5 and the sample Pe5 showed minimum alpha activity. The higher alpha activity is mainly due to the uranium and radium isotopes and it also depends on the geological characteristics of the region. Strong correlation is observed between soil samples for sieve size $0.250 \mathrm{~mm}$ and $0.025 \mathrm{~mm}$ (near the sea). This may be due to the existence of thorium present in the samples. Regression analysis is performed to determine the strength of relationship between the sampling location and the sieve size of the samples. The results obtained show a strong positive correlation existing between the samples of the sieve size $0.250 \mathrm{~mm}$ and $0.025 \mathrm{~mm}$ (near the sea, $150 \mathrm{~m}$ away from the sea). Goodness of individual fit was assessed in terms of the residual (error) sum of squares (RSS). The one-way analysis of variance (ANOVA) for gross alpha activity in soil samples show there is no significant difference at $5 \%$ level between soil samples near the sea in various locations. This could be due to small size of the sample particles. Table 1,2 shows alpha activity in the soil samples for sieve size $0.250 \mathrm{~mm}, 0.063 \mathrm{~mm}$ and $0.025 \mathrm{~mm}$ (near the sea, $150 \mathrm{~m}$ away from the sea). Table 3-8 shows correlation between soil samples for various sieve size. Table 9,10 represents ANOVA result for soil samples (near the sea, $150 \mathrm{~m}$ away from the sea). Figure 1,2 shows the gross alpha activity concentration for the soil samples near the sea, $150 \mathrm{~m}$ away from the sea. 


\section{Conclusion}

An attempt has been made to estimate the gross alpha radioactivity in the south east coastal region of Tamilnadu. The gross alpha activity concentrations of beach sand samples for various sieve size have been measured by alpha counting system. As shown in the result, the Kol sample has the highest alpha activity concentration (sieve size $0.250 \mathrm{~mm}$ ) and Aa1 and Mal sample have the lowest alpha activity (sieve size 0.025 $\mathrm{mm}$ ). The maximum alpha activity concentration is observed in Pml5 sample and minimum in Pe5 sample. The higher alpha activity concentration in the corresponding sample is due to the presence of high radioactive content in the sample. High correlation is observed between soil samples for sieve size $0.250 \mathrm{~mm}$ and $0.025 \mathrm{~mm}$ (near the sea) of the value 0.906 . The one-way analysis of variance (ANOVA) for gross alpha activity in soil shows insignificant difference at $\mathrm{p}<0.05$ due to the smaller size of the samples.

Table 1. Alpha activity in the soil samples near the sea for various sieve size

\begin{tabular}{|l|l|l|l|}
\hline \multirow{2}{*}{ Sampling Location } & \multicolumn{1}{|c|}{$\alpha(\mathrm{Bq} / \mathrm{kg})$} & \multicolumn{1}{|c|}{$\alpha(\mathrm{Bq} / \mathrm{kg})$} & \multicolumn{1}{|c|}{$\alpha(\mathrm{Bq} / \mathrm{kg})$} \\
\cline { 2 - 4 } & Sieve size $0.25 \mathrm{~mm}$ & Sieve size $0.063 \mathrm{~mm}$ & Sieve size $0.025 \mathrm{~mm}$ \\
\hline Ko1 & 3679.6 & 3517.3 & 3354.9 \\
\hline Le1 & 1515.1 & 2435.0 & 1461.0 \\
\hline Uv1 & 1190.4 & 1731.6 & 1352.8 \\
\hline Pe1 & 1569.2 & 1893.9 & 2759.7 \\
\hline Ma1 & 595.2 & 270.5 & 162.3 \\
\hline Aa1 & 216.4 & 270.5 & 162.3 \\
\hline Th1 & 378.7 & 1785.7 & 703.4 \\
\hline Ve1 & 216.4 & 378.7 & 487.0 \\
\hline Pm1 & 703.4 & 1569.2 & 1298.7 \\
\hline Mtm1 & 270.5 & 378.7 & 270.5 \\
\hline
\end{tabular}

Table 2. Alpha activity in the soil samples $150 \mathrm{~m}$ from the sea for various sieve size

\begin{tabular}{|l|l|l|l|}
\hline \multirow{2}{*}{ Sampling Location } & \multicolumn{1}{|c|}{$\alpha(\mathrm{Bq} / \mathrm{kg})$} & \multicolumn{1}{|c|}{$\alpha(\mathrm{Bq} / \mathrm{kg})$} & \multicolumn{1}{c|}{$\alpha(\mathrm{Bq} / \mathrm{kg})$} \\
\cline { 2 - 4 } & Sieve size $0.250 \mathrm{~mm}$ & Sieve size $0.063 \mathrm{~mm}$ & Sieve size $0.025 \mathrm{~mm}$ \\
\hline Ko5 & 537.6 & 591.3 & 430.1 \\
\hline Le5 & 860.2 & 752.6 & 268.8 \\
\hline Uv5 & 1344.4 & 1397.8 & 967.7 \\
\hline Pe5 & 376.3 & 215.0 & 107.5 \\
\hline Ma5 & 967.7 & 752.6 & 645.1 \\
\hline Aa5 & 483.8 & 709.6 & 268.8 \\
\hline Th5 & 215.0 & 537.6 & 430.1 \\
\hline Ve5 & 430.1 & 967.7 & 537.6 \\
\hline Pm15 & 1774.1 & 1505.3 & 860.2 \\
\hline Mtm5 & 268.8 & 322.5 & 376.3 \\
\hline
\end{tabular}

Table 3. Correlation coefficient between soil samples for sieve size $0.250 \mathrm{~mm}$ and $0.063 \mathrm{~mm}$ (near the sea)

\begin{tabular}{|l|l|l|}
\hline Sampling Location & Sieve size $0.250 \mathrm{~mm}$ & Sieve size $0.063 \mathrm{~mm}$ \\
\hline Ko1 & 3679.6 & 3517.3 \\
\hline Le1 & 1515.1 & 2435 \\
\hline Uv1 & 1190.4 & 1731.6 \\
\hline Pe1 & 1569.2 & 1893.9 \\
\hline Ma1 & 595.2 & 270.5 \\
\hline Aa1 & 216.4 & 270.5 \\
\hline Th1 & 378.7 & 1785.7 \\
\hline Ve1 & 216.4 & 378.7 \\
\hline Pml1 & 703.4 & 1569.2 \\
\hline Mtm1 & 270.5 & 378.7 \\
\hline Pearson Correlation & 0.874 & \\
Regression & 0.764 & \\
Root Mean Square Error & 10.37 & \\
Residual Sum of Square & 860.53 & \\
\hline
\end{tabular}

Table 4. Correlation coefficient between soil samples for sieve size $0.063 \mathrm{~mm}$ and $0.025 \mathrm{~mm}$ (near the sea)

\begin{tabular}{|l|l|l|}
\hline Sampling Location & Sieve size $0.063 \mathrm{~mm}$ & Sieve size $0.025 \mathrm{~mm}$ \\
\hline Ko1 & 3517.3 & 3354.9 \\
\hline Le1 & 2435 & 1461.0 \\
\hline Uv1 & 1731.6 & 1352.8 \\
\hline Pe1 & 1893.9 & 2759.7 \\
\hline Ma1 & 270.5 & 162.3 \\
\hline Aa1 & 270.5 & 162.3 \\
\hline Th1 & 1785.7 & 703.4 \\
\hline Ve1 & 378.7 & 487.0 \\
\hline Pml1 & 1569.2 & 1298.7 \\
\hline
\end{tabular}


Measurement of gross alpha activity and statistical analysis of beach sediments along ....

\begin{tabular}{|l|l|l|}
\hline Mtm1 & 378.7 & 270.5 \\
\hline Pearson Correlation & 0.876 & \\
Regression & 0.769 & \\
Root Mean Square Error & 10.39 & \\
Residual Sum of Square & 863.68 & \\
\hline
\end{tabular}

Table 5. Correlation coefficient between soil samples for sieve size $0.250 \mathrm{~mm}$ and $0.025 \mathrm{~mm}$ (near the sea)

\begin{tabular}{|l|l|l|}
\hline Sampling Location & Sieve size $0.250 \mathrm{~mm}$ & Sieve size $0.025 \mathrm{~mm}$ \\
\hline Ko1 & 3679.6 & 3354.9 \\
\hline Le1 & 1515.1 & 1461.0 \\
\hline Uv1 & 1190.4 & 1352.8 \\
\hline Pe1 & 1569.2 & 2759.7 \\
\hline Ma1 & 595.2 & 162.3 \\
\hline Aa1 & 216.4 & 162.3 \\
\hline Th1 & 378.7 & 703.4 \\
\hline Ve1 & 216.4 & 487.0 \\
\hline Pml1 & 703.4 & 1298.7 \\
\hline Mtm1 & 270.5 & 270.5 \\
\hline Pearson Correlation & 0.906 & \\
Regression & 0.821 & \\
Root Mean Square Error & 9.138 & \\
Residual Sum of Square & 668.09 & \\
\hline
\end{tabular}

Table 6. Correlation coefficient between soil samples for sieve size $0.250 \mathrm{~mm}$ and $0.063 \mathrm{~mm}(150 \mathrm{~m}$ away from

\begin{tabular}{|l|l|l|}
\hline \multicolumn{4}{l}{ the sea) } \\
\hline Sampling Location & Sieve size $0.250 \mathrm{~mm}$ & Sieve size $0.063 \mathrm{~mm}$ \\
\hline Ko5 & 537.6 & 591.3 \\
\hline Le5 & 860.2 & 752.6 \\
\hline Uv5 & 1344.4 & 1397.8 \\
\hline Pe5 & 376.3 & 215.0 \\
\hline Ma5 & 967.7 & 752.6 \\
\hline Aa5 & 483.8 & 709.6 \\
\hline Th5 & 215.0 & 537.6 \\
\hline Ve5 & 430.1 & 967.7 \\
\hline Pm15 & 1774.1 & 1505.3 \\
\hline Mtm5 & 268.8 & 322.5 \\
\hline Pearson Correlation & 0.773 & \\
Regression & 0.764 & \\
Root Mean Square Error & 10.37 & \\
Residual Sum of Square & 860.53 & \\
\hline
\end{tabular}

Table 7. Correlation coefficient between soil samples for sieve size $0.063 \mathrm{~mm}$ and $0.025 \mathrm{~mm}(150 \mathrm{~m}$ away from

\begin{tabular}{|l|l|l|}
\multicolumn{4}{l}{ the sea $)$} \\
\hline Sampling Location & Sieve size $0.063 \mathrm{~mm}$ & Sieve size $0.025 \mathrm{~mm}$ \\
\hline Ko5 & 591.3 & 430.1 \\
\hline Le5 & 752.6 & 268.8 \\
\hline Uv5 & 1397.8 & 967.7 \\
\hline Pe5 & 215.0 & 107.5 \\
\hline Ma5 & 752.6 & 645.1 \\
\hline Aa5 & 709.6 & 268.8 \\
\hline Th5 & 537.6 & 430.1 \\
\hline Ve5 & 967.7 & 537.6 \\
\hline Pm15 & 1505.3 & 860.2 \\
\hline Mtm5 & 322.5 & 376.3 \\
\hline Pearson Correlation & 0.735 & \\
Regression & 0.769 & \\
Root Mean Square Error & 10.39 & \\
Residual Sum of Square & 863.68 & \\
\hline
\end{tabular}

Table 8. Correlation coefficient between soil samples for sieve size $0.250 \mathrm{~mm}$ and $0.025 \mathrm{~mm}(150 \mathrm{~m}$ away from the sea)

\begin{tabular}{|l|l|l|}
\hline Sampling Location & Sieve size $0.250 \mathrm{~mm}$ & Sieve size $0.025 \mathrm{~mm}$ \\
\hline Ko5 & 537.6 & 430.1 \\
\hline Le5 & 860.2 & 268.8 \\
\hline Uv5 & 1344.4 & 967.7 \\
\hline Pe5 & 376.3 & 107.5 \\
\hline Ma5 & 967.7 & 645.1 \\
\hline Aa5 & 483.8 & 268.8 \\
\hline Th5 & 215.0 & 430.1 \\
\hline
\end{tabular}


Measurement of gross alpha activity and statistical analysis of beach sediments along ....

\begin{tabular}{|l|l|l|}
\hline Ve5 & 430.1 & 537.6 \\
\hline Pm15 & 1774.1 & 860.2 \\
\hline Mtm5 & 268.8 & 376.3 \\
\hline Pearson Correlation & 0.774 & \\
Regression & 0.821 & \\
Root Mean Square Error & 9.138 & \\
Residual Sum of Square & 668.09 & \\
\hline
\end{tabular}

Table 9. ANOVA result for soil samples near the sea

\begin{tabular}{|l|l|l|l|l|l|l|}
\hline Source & SS & df & MS & F & p-value & F-critical \\
\hline Between groups & 763893 & 2 & 381946.5 & 0.3236 & 0.7262 & 3.3541 \\
Within groups & 31860512.12 & 27 & 1180018.96 & & & \\
\hline Total & 32624405 & 29 & & & & \\
\hline
\end{tabular}

Table 10. ANOVA result for soil samples $150 \mathrm{~m}$ from the sea

\begin{tabular}{|l|l|l|l|l|l|l|}
\hline Source & SS & df & MS & F & p-value & F-critical \\
\hline Between groups & 467316.72 & 2 & 233658.36 & 1.3836 & 0.2678 \\
Within groups & 4559437.49 & 27 & 168868.05 & & 3.3541 \\
\hline Total & 5026754 & 29 & & & & \\
\hline
\end{tabular}

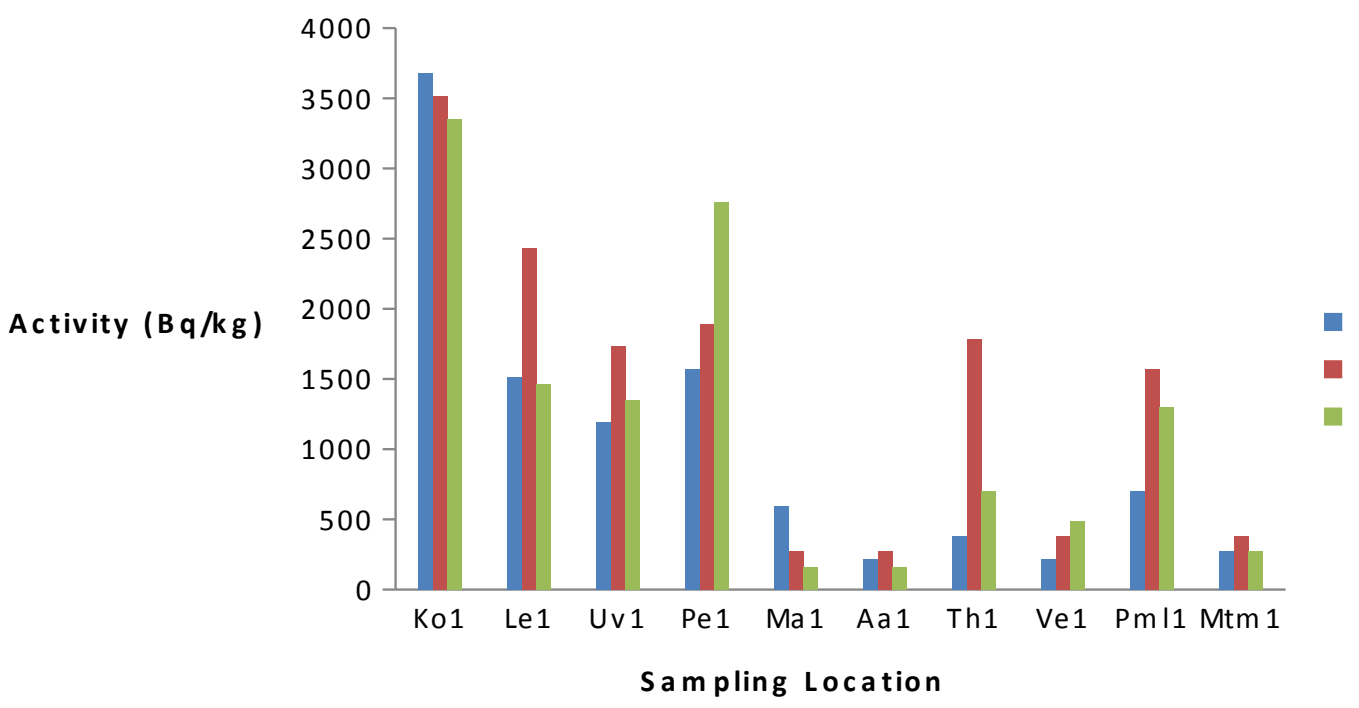

Fig 1. Alpha activity in the soil samples near the sea for various sieve size

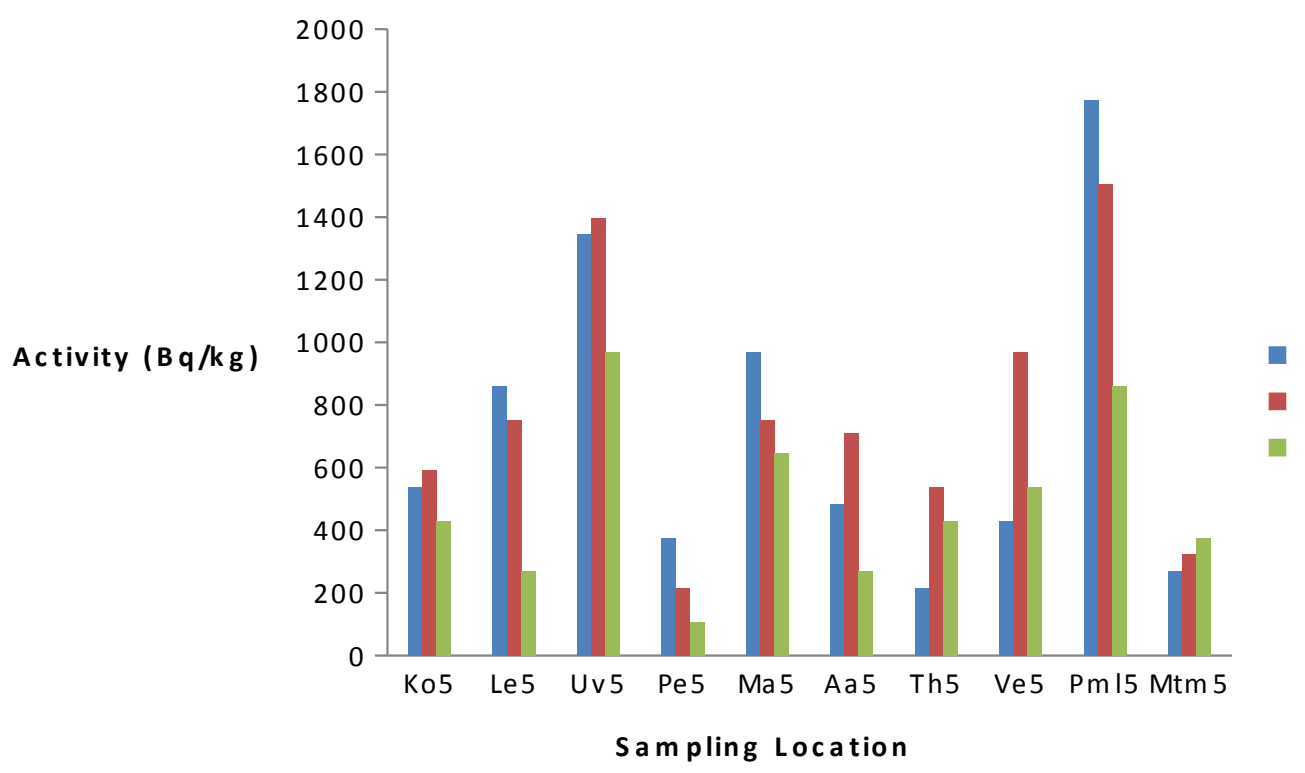

Fig 2. Alpha activity in the soil samples $150 \mathrm{~m}$ from the sea for various sieve size 


\section{References}

[1]. Miller K.M. and Shebell P. In situ gamma ray spectrometry. A tutorial for environmental scientists, USDOSE publication, EML-557 (New York: Environmental Measurement Laboratory) 1993.

[2]. Hazrati S, Baghi AN, Sadeghi H, Barak M, Zivari S, Rahimzadeh S, Investigation of natural effective gamma dose rates case study: Ardebil Province in Iran. Iranian J Environ Health Science \& Eng, 9:1, 2012.

[3]. Malanca A., Pessina V., Dallara G., Assessment of the natural radioactivity in the soils around the coast of Rio Grande Do Norte, Health Physics, 64, 1993.

[4]. Ahmed N. Matiullah, Khatibeh A.J.A.H., Ma'ly A. and Kenwy M.A., Measurement of natural radioactivity in Jordanian sand, Radiat. Meas. 28, 341-344, 1997.

[5]. Trevisi R., Bruno M., Orlando C., Ocone R., Paolelli C., Amici M., Altieri A., and Antonelli B., Radiometric characterization of more representative natural building materials in the province of Rome. Radiat. Prot. Dosim. 113, 168-172, 2005.

[6]. Sroor A., El-Bahi S.M., Ahmed F., Abdel-Haleem A.S., Natural radioactivity and radon exhalation rate of soil in southern Egypt, Appl. Radiat. Isot 55, 873-879., 2001.

[7]. Singh S., Singh B., Kumar A., Natural radioactivity measurements in soil samples from Hamirpur district., Radiat. Meas. 36, 547549, 2003.

[8]. Kurnaz A., Kukukomeroglu B., Keser R., Okumusoglu N.T., Korkmaz F., Karahan G., Cevik U., Determination of radioactivity levels and hazards of soil and sediment samples in Firtina Valley (Rize, Turkey), Appl. Radiat. Isot. 65, 1281-1289, 2007.

[9]. Narayana Y., Somashekarappa H.M., Kurunakara N., Avadhani D.N., Mahesh H.M., Sidappa K., Natural radioactivity measurements in the soil samples of coastal Karnataka of South India, Health Physics, 80, 24-33, 2001.

[10]. Dabayneh K., Soroor A., and Abdel Haleem S., Environmental nuclear studies of natural and man-made radioactivity at Hebron region in Palestine, Journal of Al-Quds Open University, 12(1), 23-42, 2008. 